\title{
TroyAcademy
}

International Journal of Social Sciences

\section{Turizmde Çekicilik Unsuru Olarak Dağıstan Mutfağı: Güneyköy Örneği}

\author{
Araştırma Makalesi/Research Article
}

\section{Hatice GÜÇLÜ NERGIZ* Evrim KARACA**}

\section{ÖZET}

Yemek ve mutfak kültürü, toplumların kimliğini ve özelliklerini yansıtan kültürel miras unsurlarındandır. Aynı zamanda, mutfak kültürü turizm ürününde önemli bir çekicilik unsurudur. Çekicilik bir bölgeye veya mekâna turistin gidip gitmemesinde etkili olan yöreye özgü cezbedici faktörler olarak tanımlanabilir. Bu çekicilik faktörleri arasında yöresel mutfaklar artan bir öneme sahiptir. Günümüzde kültürel miras öğesi olarak yöresel yiyecekler ve ürünlerin sürdürülebilir bir boyutta ele alınarak, gelecek nesillere aktarılması da son derece önem taşımaktadır. Araştırma konusunu teşkil eden Dağıstan mutfağı Türk mutfak kültürünü etkileyen ana etnik topluluklardan biridir. Yalova ilinde yaşayan ve bu yörenin mutfak kültürünün şekillenmesinde rol oynayan topluluklardan biri Dağıstanlılardır. Bu çalışmada, Yalova ili Güneyköy'de bulunan Dağıstanlıların yemek kültürü ve özelliklerinin ortaya konması amaçlanmıştır. Çalışmada, nitel araştırma yöntemi kullanılarak, Güneyköy'de Dağıstan göçmenleri ile yapılan yüz yüze görüşmelerden elde edilen bilgiler sunulmuştur. Sonuçlar, Yalova Güneyköy'de Dağıstan mutfağında üzüm sirkesi ve sarımsağın ağırlıklı olarak kullanıldığını, hamur işlerinin fazla tercih edildiği bu mutfakta yapılan geleneksel lezzetlerin yöreye gelen ziyaretçiler tarafindan da tercih edildiğini ortaya koymaktadır.

Anahtar Kelimeler: Yemek Kültürü, Yöresel Mutfak, Dă̆ıstan Mutfăğı, Güneyköy.

\section{Dagestan Cuisine as an Element of Attraction in Tourism:}

\section{A Case Study of Guneykoy Village}

\begin{abstract}
Food and cuisine culture is one of the cultural heritage elements that reflect the identity and characteristics of societies. Cuisine culture is also an important element of attraction in tourism product. Attraction can be described as region-specific attraction factors that are effective on whether a tourist can go to a region or place. Local cuisines, one of these attraction factors, are of increasing importance. Nowadays, it is crucial that local dishes and products are handled in a sustainable dimension and transferred to the next generations as an element of cultural heritage. Dagestan cuisine being the subject of research is one of the main ethic communities that affect Turkish cuisine culture. The people of Dagestan are one of the communities that live in Yalova province and play a role in shaping the cuisine culture of this region. The purpose of this study is to reveal the food

* Doç. Dr., Kocaeli Üniversitesi Turizm Fakültesi Turizm İşletmeciliği Bölümü, Kartepe/ Kocaeli, hg.nergiz@kocaeli.edu.tr, ORCID ID: https://orcid.org/0000-0002-8848-7014

** Öğr. Gör., Sakarya Uygulamalı Bilimler Üniversitesi Sapanca Turizm Meslek Yüksekokulu Otel, Lokanta ve İkram Hizmetleri Bölümü, Sapanca/ Sakarya, evrimkaraca@ subu.edu.tr, ORCID ID: https://orcid.org/0000-0003-25205195
\end{abstract}


culture and characteristics of the people of Dagestan in Guneykoy in Yalova province. Using the qualitative research method, information obtained from face-to-face interviews with the migrants of Dagestan was presented in this study. The results have demonstrated that grape vinegar and garlic are used predominantly in Dagestan cuisine in Guneykoy in Yalova, and local tastes prepared in this cuisine, where pastries are highly used, are also preferred by visitors to the region.

Keywords: Cuisine Culture, Local Cuisine, Dagestan Cuisine, Guneykoy.

\section{GíRiş}

Yemek ve mutfak kültürü, toplumların kimliğini ve özelliklerini yansıtan kültürel miras unsurlarındandır. Geçmişten gelen mutfak kültürlerine ait pek çok özelliği bir bölümü nitelik değiştirerek, bir bölümü ise halen özelliklerini koruyabilmektedir. (Karaca ve Sarışık, 2018: 2). Yöresel mutfak, yörenin diğer çekiciliklerini tamamlayıcı bir ürün olarak kabul görebileceği gibi, bağımsız olarak tek başına cazibe unsuru olarak da ele alınabilir (Okumus vd., 2013; Şengül ve Genç, 2016). Bir destinasyonun kimliğine katkıda bulunan yöresel mutfak, birçok gezgin için seyahat deneyiminin ayrılmaz bir parçasıdır (Jalis vd., 2014: 103). Yöresel mutfaklar günümüzde gastronomi turizmi kapsamında ele alınarak, turistik çekicilik unsuru olarak değerlendirilmektedir. Yöresel mutfakların kendilerine has özelliklerinin vurgulanması, farklıklarının ön plana çıkarılması ile çekicilikleri artırılabilir. Böylece diğer rakip yöreler karşısında rekabet üstünlüğü sağlanabilir.

Son yıllarda yöresel ürünler giderek daha ilgi çekici olmaya başlamıştır. Seri üretimde elde edilebilen ürün çeşitliliğine rağmen, ürünün tüketicilerde yarattığı memnuniyet kalitesi eşit değildir. Yöresel ürünler, müşteriler tarafindan değişik lezzette daha iyi ürünler olarak değerlendirilmektedir (Charzyński vd., 2017: 11). Bessiere (1998) geleneksel yemeklere ve mutfağa sahip kırsal destinasyonların önemli turistik yerler olabileceğini belirtmiştir. Long (2004: 2) "yiyecekleri turizm için hem bir varış noktası hem de bir araç olarak keşfedilmesi" gerektiğini ifade ederek, turizmde yiyeceklerin önemini vurgulamıştır. Buna benzer bir saptama Mil ve Denk (2015) tarafından da ifade edilmiştir. Araştırmacılar, turizm faaliyetlerini çeşitlendirmede kültürel özelliklere ve gastronomi kültürlerine önem verilerek turizm gelirlerinin artırılabileceğini iddia etmiştir. Yöresel mutfağa ait niteliklere sahip mutfaklardan biri de Dağıstan mutfağıdır. Bu çalışmada, yöresel mutfaklar içinde Dağıstan mutfağının turizmde bir çekicilik unsuru olabilmesine yönelik ilk aşamayı oluşturan yöre mutfağının özelliklerinin ortaya çıkarılması hedeflenmektedir. Eldarov vd. (2017), Dağıstan mutfağının sahip olduğu zenginliklere rağmen, henüz Dağıstan'ın bir mutfak markası olarak konumlandırılmadığını ifade etmektedir.

Günümüzde kültürel miras öğesi olarak yöresel yiyecekler ve ürünlerin sürdürülebilir bir boyutta ele alınarak, gelecek nesillere aktarılması da son derece önem taşımaktadır. Araştırma konusunu teşkil eden Dağıstan mutfağı Türk mutfak kültürünü etkileyen ana etnik topluluklardan biridir. Yalova ilinde 
yaşayan ve bu yörenin mutfak kültürünün şekillenmesinde rol oynayan topluluklardan biri olan Dağıstan yemek kültürünün ve Dağıstan topluluğunun özelliklerinin ortaya konması amaçlanmıştır.

\section{1. ÇEKİCİLIK UNSURU OLARAK YÖRESEL MUTFAKLAR}

Turizm kapsamında, bir yöredeki ürün ve hizmetlerin ilgi çekebilmesi önem taşımaktadır. Çekicilik; bireyin turizm amaçlı gitmek istediği yerler arasında tercih edip gitmesini sağlayan faktörler, olarak ifade edilmektedir (Kozak vd., 2008). Başka bir ifadeyle çekicilik; bir bölgede turistleri cezbedecek nedenlerdir. Bunlar; farklı doğal çekicilikler, kültürel çekicilikler, ekonomik çekicilikler, yiyecekiçecek çekicilikleri ve benzeri özellikleri sağlayan mekânlardır (Duman ve Öztürk, 2005). Turizm ürününde çekiciliği sağlayan başlıca beş faktör bulunmaktadır. Bunlar (Kozak vd., 2008):

Doğal Unsurlar: Bölgenin coğrafik durumu, iklimi, doğal güzellikleri, doğal kaynakları, güneşli gün sayısı ve yağmurlu gün sayısı. Kışın kar yüksekliği ve karın kış mevsiminde kalma süresi, hayvan türleri ve benzeri etkenlerdir.

Sosyo-Kültürel Unsurlar: Turizm amaçlı seyahat edilecek yerin kültürel değerleri bölgenin doğal güzellikleri kadar çekicilik unsuru oluşturmaktadır. Bölge halkının gelenek ve görenekleri (bayramlar, doğum, düğün vb.), kültürel varlıkları (anıtları, tarihi yapıları, ibadet yerleri, vb.) bölgenin sosyokültürel yapısı, tek başına ilgi odağı olabilecek etkenler şeklinde düşünülebilir.

Ekonomik Unsurlar: Bölgenin turizm ürünü açısından talep edilmesinde ve satın alınmasında o günün ekonomik koşullarına uygunluğu (turistik ürün fiyatı, ülkenin genel ekonomik durumu, paranın satın alma değeri, turizm ekonomisinin durumu) çekicilik unsuru olarak değerlendirilmektedir.

Psikolojik Unsurlar: Ülkeler arasındaki siyasi, tarihsel ve kültürel ilişkiler, gelenek ve görenekler, toplumun davranış biçimleri, günün moda ve alışkanlıkları, sempati ve veya iticilikler ve benzeri faktörler psikolojik çekicilik unsurlarıdır.

Ulaşılabilirlik: Talep edilen bölgenin çekiciliğini oluşturabilecek bir diğer unsur ise turizm bölgesi için talep edilen yerin ulaşılabilirliği, ulaşım olanakları ve buna bağlı olarak ulaşılabilirlikte alt yapı düzeyi önemlidir. Satın alınacak turizm hizmeti için bölgenin ulaşılabilirlikteki çekiciliğinde; karayolu, denizyolu, havayolu gibi ulaşım ağının gidilecek hedefteki yere ulaşım ağının sağlanması açısından önemlidir.

Günümüzde sıralanan çekicilik faktörlerine ilave edilebilecek unsurlar arasında yöresel mutfaklar da yer edinmiştir. Yöresel mutfak, bir bölgeye, yöreye ait, yiyecek, içecek ve sofra alışkanlıklarını ifade eden bir kavramdır. Yöresel mutfak, "özel bir yöreye ait olan, o yörenin kültüründen izler taşıyan, bölgeye özgü ürünler ve adetlerin birleşimiyle ortaya çıkan, yöre pişirme tekniklerinin kullanılması ile yapılan, dini ya da milli sebeplerle de oluşabilen, yöre insanları tarafından ayrıcalıklı tutulan 
yemeklerin ve içeceklerin bütünü” dür (Şengül ve Türkay, 2015: 4). Cohen ve Avieli (2004) tek tek şehirlerin ve hatta bütün ülkelerin kendi benzersiz mutfaklarının çekici bir cazibe merkezleri olabileceğini iddia etmektedir. Jalis vd. (2014), yerel yemek ve mutfaklarla ilgili bilgiler ve görsellerin de turist destinasyonlarının pazarlama materyallerinde giderek daha fazla yer aldığını ifade etmektedir. Yöresel mutfaklar, turizmde çekicilik unsuru olarak değerlendirilerek önemli bir rekabet aracı olarak kullanılabilir (Avcıkurt, 2005: 9). Selwood (2003), bir yöreyi ziyaret eden turistlerin, yöreye, bölgeye ait kültürel yemekleri, deneyimlemeleri turistik ziyaret sırasında yaptıkları faaliyetlerin başında geldiğini, Quan ve Wang (2004) ise yerel yemeklerin, turistlerin bir destinasyondaki tatillerine değer katan turistik deneyimlerinin önemli bir unsuru olduğunu saptamıştır. Yöreye özgü kültürel yiyecekiçecek mirasını diğer yörelerden ayıran, yörenin kendi mutfağıdır (Long, 2004). Yöresel mutfaklara ait olan unsurlar geçmişten günümüze değişime uğramadan ulaşabileceği gibi, yörede yaşayan farklı kültürlerin birleşimi ile de ortaya çıkabilmektedir (Şengül ve Türkay, 2014: 2). Bir bölgedeki yemek kültüründeki yaşam biçimi, yemeklerin hazırlanışı ve sunumunda kullanılan malzemeler önemli bir etkiye sahiptir. Yöresel mutfağın turizm çekiciliği; turizmdeki diğer seyahat çeşitlerine ve buradaki çekiciliklerinin tam tersine herhangi bir günün herhangi bir zamanında ve tüm hava koşullarında yapılabilmektedir (Kivela ve Crotts, 2009).

Gastronomi turizmi çerçevesinde değerlendirilen yöresel yiyecek ve içeceklerin tüketiminin, ziyaret edilen bölgenin kültürüne yakınlaşma ve ilgi uyandırma özelliğine sahip olduğu bilinmektedir. Ayrıca yerel halkın yaptığı, yöreye özgü yiyecek ve içecekler, turistlerin yöreyi diğer rakiplerinden farklı algılamasını sağlamaktadır (Haven-Tang ve Jones, 2006). Turizm pazarının önemli bir parçası haline de gelen bu tercihlerin yerel halk ve ekonomi üzerinde etkileri bölge çapında önemli bir kazanç unsuru olabilmektedir (Şengül ve Türkay, 2015). Aynı zamanda yöresel gastronomik ürünler, kalış süresi ve sezon uzatıcı etkisinin yanı sıra turist harcamalarını da arttırıcı etki gösterebilmektedir (Çalışkan, 2013).

$\mathrm{Bu}$ nedenle, bir destinasyon imajının ürün ve deneyimlerin çeşitliliğinin bir parçası olarak yerel mutfağın kullanılması, bir turist destinasyonunun kimliğini ve rekabet gücünü güçlendirmeye yardımc1 olabilmektedir (Jalis vd., 2014: 103).

Yöresel mutfaklar çekicilik unsuru olarak turizm deneyiminin bölünmez bir parçası olarak değerlendirilmelidir (McKrecher vd., 2008). Turistlerin aynı yöreyi tekrar tercih etmelerinde yöresel mutfak unsurları etkili olmaktadır. Ayrıca yöresel mutfak unsurları yörenin başka bir seyahat esnasında yakın bir çevrede ya da yol üstünde olması nedeni ile de tekrar tercih edilmesini sağlayabilmektedir (Şengül ve Türkay, 2018). Sonuç olarak yöreye gelen turistlere yöresel yemekleri tatma olanağ 1 
sunabilen işletmelerde üretilen yöresel yemeklerin yöreyi ziyaret eden turistler için önemli bir çekim unsuru oluşturduğu söylenebilir (Hacioğlu vd., 2009). Özbay ve Çekin (2020), Kars'a Doğu Ekspresi ile seyahat eden yolcular arasında yaptıkları bir araştırmada Kars’a gelen turistlerin konaklama tesislerinde oda-kahvaltı konakladıklarını ve şehirde geçirdikleri zaman içerisinde sabah kahvaltısı dışında diğer öğünlerini geleneksel restoranlardaki yöresel yemeklerden yemeyi tercih ettiklerini saptamışlardır. Bu bilgi de yöresel ürünlerin turizmde bir çekicilik unsuru olduğunu ve turistler tarafından tercih edildiğini destekleyen bir bulgudur.

Turistik ürünü oluşturan ve birleşik veya ayrı ayrı değerlendirildiğinde bir çekim unsuru olabilen tüm değerlerin ortaya çıkarılması ve sürdürülebilirliğinin sağlanması önem taşımaktadır. Bu açıdan ele alındığında özellikle doğal, kültürel, tarihi ve sanatsal varlıklar açısından Türkiye büyük kaynaklara sahiptir. Toplumların kültürel değerlerinden biri olarak algılanan yemek, insanın var olduğu tüm zamanlarda farklı nitelikler gösterse de hep var olmuş bir olgudur. Bu olgu, kültürel bir değer taşıdığ1 gibi aynı zamanda insanların birbirine yakınlaşmasında önemli bir köprü görevi de görmektedir. Turistik bir destinasyonu ziyaret eden turistler, söz konusu destinasyonun mutfak kültürünü de yakından tanıyabilme ve deneyimlemeyi arzu etmektedirler (Öney, 2013). Yemek kültürleri incelendiğinde, coğrafyanın yemek kültürünü yakından etkilediğini ifade etmek mümkündür. Anadolu'da farklı kültürel yapılardan olan insanların iç içe yaşamasının getirmiş olduğu zenginlik Türk mutfak kültürünü de olumlu yönde etkilemiştir. Türkiye'de her yörede kendine has pişirme teknikleri ve yemek kültürü bulunmaktadır (Maviş, 2003). Bu farklılıklar yakın iller arasında bile değişiklikler gösterebilmektedir.

\section{DAĞISTAN KÜLTÜRÜNÜN İZINDE: YALOVA GÜNEYKÖY}

Yalova, Prehistorik çağda bir geçit yeri konumunda olup, bölgede M.Ö.1200 yılında Frigler, M.Ö. 700 yıllarında Bitinyalılar egemen olmuştur. Bizanslılardan sonra bir süre Selçukluların yönetimine giren kasaba, Haçlı Seferleri zamanında ağır hasar almıştır. Daha sonra Osman Bey’in komutanlarından Yalvaçoğlunca ele geçirilen yöre 1867'de Hüdavendigar (Bursa) Vilayet Merkez Sancağı'na bağlı bir kaza iken, 1901'de bağımsız İzmit Sancağı'na bağlanmıştır. Atatürk'ün isteği üzerine 1930'da İstanbul'a bağlanmıştır. Yalova, 6 Haziran 1995'de il merkezi olarak ilan edilmiştir (Yalova Doğa Turizmi Master Planı, 2012). Merkez ilçeye bağlı bir köy olan Güneyköy, Yalova- Bursa karayolu üzerinde yer almaktadır. Yalova'nın en güney sınırını oluşturan bu köyün doğusunda Sugören köyü, batısında Samanlı Dağları ve Kurtköy, kuzeyinde Esadiye, güneyinde Orhangazi bulunmaktadır (Zengin, 1987).

Köy, 1884-1893 yıllarında Kafkasya'dan göç eden 60 ailenin bu bölgeye yerleştirilmesi ile kurulmuştur. Köyün kuruluşuna ilişkin tarihi belgelerden, köyün yüksek dağlar arasında sıkışmış, ufak 
bir vadi üzerinde kurulduğu, etrafının taşlık ve pırnal ağaçları ile kaplı olduğu tespit edilmiştir. Arazinin, tarıma uygun olmaması nedeni ile köylülerin odunculuk ve kömür işi ile geçimini sağladığı yazılı kaynaklardan anlaşılmaktadır (Keskin, 2015). Sultan Reşat'ın köye olan özel ilgisi ve katkıları nedeniyle köyün ismi "Reşadiye" olarak değiştirilmiştir. 1934 yılına kadar bu adla bilinen köyün adı İstanbul il sınırlarının en güney kısmında kalması nedeni ile daha sonra "Güneyköy" olarak değiştirilmiştir. Yalova'ya yerleştirilen Kafkasyalı bir kabile olan Dağıstanlılar, Güneyköy’ü planlı bir şekilde kurmuşlardır (Kılıç, 2020: 69).

Güneyköy'de bulunan eski eserler arasında Sultan Reşat adına yaptırılan Sultan Reşat Çeşmesi'dir (Resim 1). Yüksekliği:3 metre $65 \mathrm{~cm}$, genişliği ise 2 metre $20 \mathrm{~cm}$. olan çeşme çift taraflı, hazneli, semerdam çatılıdır. Sivri kemerli olan çeşmede “denizlerin ve karaların padişahı Sultan Reşat hakkın dostu ve tevkifine mazhar bütün himmeti şahanesi hayra yakın cenabı hak onu hayırların ecrine nail etsin bu çeşmeden su içenler şad olsun şifaya kavuşsun susayanlar su içmekten asla geri kalmasın”" şeklinde yazılmıştır.

Çeşme Kocaeli Kültür Varlıklarını Koruma Bölge Kurulu'nun 09.09.2008 tarih 530 sayılı kararı ile tescil edilmiştir (https://www.kulturportali.gov.tr/turkiye/yalova/kulturenvanteri/mehmet-resat-hancesmesi).

Güneyköy'de yer alan eski eserlerden bir diğer ise köy meydanında bulunan binadır (Resim 2). Bu tarihi bina (14 pafta, 1176 parselde), Bursa Kültür ve Tabiat Varlıklarını Koruma Bölge Kurulu tarafından 2007 yılında tescil edilmiştir. Orta sofalı Türk evi plana sahip olan ev, iki katlıdır. Zemin katı kargir, üst katı ahşap karkas konstrüksiyonda yapılmıştır. Ön cephedeki balkon ve üst kat pencereleri geleneksel mimari tarzındadır (http://yalovakentmuzesi.gov.tr/tarihi-eserler/yalovamerkez-ilce-guneykoyde-bina/).

Kafkasya'dan göç eden ve kuyum işi ile ünlü olan Dağıstanlılar Güneyköy’de de bu el sanatlarına devam etmişlerdir (Resim 3). Yukarıda da ifade edildiği gibi arazinin tarıma uygun olmaması, halkın bu uğraşısına devam etmesinde de etken olduğu ifade edilebilir. Yörede, gümüş- bakır oksit ve boynuzdan takı yapımına devam edilmektedir. El işlemeciliğinde sığır boynuzları suda kaynatılarak iç dokusundan ayrıldıktan sonra, yapılacak dokuya göre dikey veya boydan boya iki parçaya ayrılarak sitrik asit, sülfürik asit karışımlı suyla kaynatılarak yumuşatılması sağlanarak, presleme ile düzeltilmektedir. Yapılacak takılara göre şekil çizili kıl testere ile kesilmektedir. Bu işleme kaba işlem adı verilmekte, bir sonraki aşamada yapılacak şekillerin alt ve yanlarına gümüş uygulaması yapılarak kakma işlemine geçilmektedir. Kakmalara natürel mercan, firuze vb. taş 925 ayar sannel tabir edilen içi boş boru uygulanarak takı hazır hale getirilir. Ürünlerde kullanılan teknik yaldız el işçiliğidir. 
Köyde Mehmet Atışan tarafından yapılan takılar T.C. Kültür ve Turizm Bakanlığı tarafından internet ortamında satışı yapılmaktadır (http://www.kulturportali.gov.tr/turkiye/yalova/nealinir/boynuz-vegumus-sleme-takilar). Halkın bir diğer geçim kaynağı ise kuyumculuk zahmetli bir iş olduğundan ustaların sayısı azalmıştır. Güneyköy’de sayıları azalan kültürel değerlerden biri olan bu el sanatının korunması için de çalışmaların yapılması önem taşımaktadır.

\section{YÖNTEM}

Araştırma, nitel araştırma yöntemine göre tasarlanmıştır. Nitel araştırma, "gözlem, görüşme ve belge analizi gibi nitel veri toplama yöntemlerinin kullanıldı̆̆ı, algıların ve olayların doğal ortamda gerçekçi ve bütüncül bir biçimde ortaya konmasına yönelik nitel bir sürecin izlendiği araştırmaları” ifade etmektedir (Yıldırım ve Şimşek, 2006: 39).

Nitel araştırma yöntemlerine göre yürütülen araştırmada veriler görüşme (mülakat) tekniğiyle toplanmıştır. Görüşme “en az iki kişi arasında sözlü olarak sürdürülen bir iletişim sürecidir (Büyüköztürk vd., 2019). Görüşme, "katılımcıya bir dizi açık uçlu soruların sorularak belirli bir konu üzerindeki düşünceleri hakkında bilginin toplanması" (Kozak, 2015: 89) olarak ifade edilmektedir. Sözlü iletişim yolu ile verilerin toplandığı bu çalışmada kavramsal çerçeveyi oluşturmak ve görüşme sorularını nitelikli hazırlamak amacıyla konu ile ilgili literatür taraması yapılmıştır. Bu çalışmada, genel hatları ile görüşmede sorulacak sorular belirlenmiştir. Burada genel bir yol haritası çizilmiştir, ancak katılımcıların görüşmeye katılımlarına göre farklı soruların sorulması, ekleme ve çıkarmaların yapılarak konunun geniş bir boyutta ele alınması hedeflenmiştir.

\section{1. Çalışma Grubu}

Araştırmada görüşmeler Yalova iline bağlı Güneyköy'de yaşayan Dağıstan göçmenleri ile yapılmıştır. Köye ilk ziyaret öncesinde araştırmacılar tarafından köy hakkında bilgiler toplanmıştır. İlk ziyaret Yalova İl Kültür ve Turizm Müdürlüğü’ne gerçekleştirilmiştir. Bu ziyaretin ardından ikinci ziyaret ise çalışma sahası olan Güneyköy’de gerçekleştirilmiştir. İlk olarak köy muhtarlığı ziyaret edilmiş, araştırmacıların kendilerini tanıtmasında sonra, çalışmanın amacı açıklanarak, araştırma hakkında ön bilgiler verilmiştir. Burada köydeki nüfus, geçim kaynakları ve köyün geçmişine ilişkin bilgiler elde edilmiştir. Dağıstan kültürüyle özdeşleşmiş yemekleri daha geniş bir açıdan incelemek ve yemek geleneklerini tanımlamak için birbirinden bağımsız zaman dilimleri içerisinde araştırmaya katılmayı gönüllü kabul eden kişilerle yüz yüze mülakatlar gerçekleştirilmiştir. Mülakatlar 2019 yılı Ekim ay1 içerisinde katılımcıların belirledikleri tarih ve saatlerde kendi mekânlarında yapılmıştır. Katılımcılardan gerekli izin alınmıştır. Araştırma, 12 kişi ile gerçekleştirilmiştir. Çalışmanın kapsamı, sadece Yalova ili Güneyköy’de yerleşen Dağıstanlılar ile sınırlı tutulmuştur. Yapılan görüşmeler 
neticesinde konu, başlıklar altında ele alınarak derlenmiştir. Kaynak kişilerden yemek tariflerine ilişkin alınan malzeme listeleri standart bir ölçü listesine göre yeniden düzenlenmiştir.

\subsection{Araştırma Etiği}

Araştırma etiğgi, "varsayımın belirlenmesinden yayının tamamlanmasına kadar geçen sürecin tüm aşamalarında, bilimsel ahlâka özen gösterme” (Boydak, 2011: 17) yi ifade eder. Bu araştırmanın tasarımından başlayarak, raporlaştırılmasına kadar geçen süreçte gerek atıf verme gerekse çalışmanın araştırma bölümünün hazırlanmasında bilimsel etik kurallarına uyulmuştur. Çalışmada yürütülen araştırmanın amacı, Güneyköy'de yaşayan Dağıstanlıların yemek kültürlerini ortaya koyabilmektir. $\mathrm{Bu}$ doğrultuda köyde yaşayan yerel halk ile gerçekleştirilen görüşmelerde gönüllülük esasının temel olduğu vurgulanmıştır. Ardından, çalışmanın amacına ulaşması için katılımcılardan içtenlikle soruları cevaplamalarının beklendiği ifade edilmiştir. Çalışma için etik kurul onayı alınmıştır.

\subsection{Veri Toplama Aracı ve Verilerin Analizi}

Araştırmanın amacı, "Dağıstanlıların mutfak kültürü’ne ilişkin bilgiler elde etmektir. Bu amaç doğrultusunda ilk olarak literatür taraması yapılarak şu soruların yer aldığı bir soru formu oluşturulmuştur. Dağıstanlıların sabah, öğle ve akşam öğünlerinde tüketilen yemekler, yemeklerin pişirilme teknikleri, özel günlerde yapılan yemekler, yemeklerin yapılışı, yapılan yemekleri geçmiş ve günümüz açısından değerlendirmeleri istenmiştir.

\subsection{Bulgular}

Gerçekleştirilen görüşmelerden elde edilen ham veriler bilgisayar ortamında yazıya geçirilerek, ardından sorular doğrultusunda veriler analiz edilmiştir. Bu doğrultuda ilk olarak Dağıstan mutfağına özgü olarak Güneyköy’de hazırlanan yemeklerde kullanılan bazı özel ürünlerin olduğu saptanmıştır. Verilen bilgiler doğrultusunda bu ürünler:

Üzüm Sirkesi: Üzüm sirkesi köy kadınları tarafından kışlık hazırlık ürünleri için hazırlanan ve iç harcı etli hamur işi yemeklerinde bolca üzüm sirkesi kullanılır.

Sarımsak: Sarımsak Güneyköy halkı tarafından tüm öğünlerde yapılan yemeklerde yardımcı malzeme olarak oldukça fazla kullanılan lezzet verici üründür.

Güneyköy’de elde edilen bilgiler 1şığında; köyde Dağıstanlılara özgü yemeklerin büyük bölümünün hala yapıldığı saptanmıştır. Geçmişte yapılan yemekler ile günümüzde yapılan yemekler arasında çok fazla fark olmadığı ortaya çıkmıştır. Köy halkı kültürlerinde var olan yemekleri belli özel günlerde yapılan yemekler gibi kenara ayırarak yapımını bırakmamışlardır. Cenaze merasimlerinde, düğünlerde, mevlitlerde, günün diğer öğünlerinde de benzer yemekler yapılmaktadır. Pişirme 
yöntemlerinde en çok haşlama yöntemi kullanılmakta olup, yağda kızartma tekniği ise genelde kullanılmamaktadır.

Güneyköy’de Dağıstan kültürüne özgü olarak Dağıstan helvası veya “Bakuk” olarak adlandırılan un helvası yapılmaktadır. Bakuk, gelenek olarak bayramlarda yapılan tatlı grubuna giren şekli kurabiyeyi andıran, şerbetsiz bir helva çeşididir. Bakuk, Dağıstan'da ölümlerde taziyeye gelen kişilere ikram edilmek üzere yapılmakta iken, Yalova'da bulunan Dağıstan kökenli halkın bu geleneği geçmişte yaparken, günümüzde sadece cenazelerde dağıtılan bir helva türü olmaktan çıktığı gözlemlenmektedir. Bazı kaynaklarda bu helva "Pakuk” olarak adlandırılmaktadır. Bu helvaya "ölü helvası" (Şutanrıkulu, 2015: 146) da denilmektedir. Helva, Osmanlı Mutfăğ'nda da geleneksel tatlı kültüründe yaygın olan tatlı türlerinden biri olarak dikkat çekmektedir (Ünyay Açıkgöz, 2019).

\section{Bakuk Dağıstan Helvası}

\section{Malzemeleri}

- $1 \mathrm{~kg}$ un

- 500 gr tereyağ 1

- 750 gr elenmiş pudra şekeri

Yapılışı: Tereyağı geniş tencereye alınarak yağ erimeden üzerine un konur ve tahta bir kaşıkla sürekli kısık ateşte karıştırılarak bir buçuk saat kavrulur. Un rengi hafif pembemsi rengini alınca üzerine elenmiş pudra şekeri ilavesiyle kavrulmaya devam edilir. Kum görüntüsü şeklindeki helva, ayrı bir yerde üzerine hafif pudra şekeri serpilmiş tepsiye dökülür. Helva üzeri altı düz bir kap ile yüzeyi sıkıştırılarak düzleştiriliyor işlemi birkaç defa tekrarladıktan sonra helva yüzeyi düzeliyor ve helva soğumadan bıçak yardımıyla baklava dilimleri şeklinde kesiliyor ve bir gece soğumaya bırakılarak dinlendiriliyor. Ertesi gün, yağ ile un özleşerek birbirlerinden ayrılmadan kalıp şeklinde tutulacak hale geliyor ve bu şekilde servis ediliyor.

\section{Karşi Dağıstan Muhallebisi}

\section{Malzemeleri}

- 500 gr kuru kayısı

- 40 gr un

- Ketentohumu yağı

- 250 gr toz şeker

- $800 \mathrm{ml} \mathrm{su}$ 
Yapılışı: Kayısı suyun bir kısmı ile haşlanır ve doğrayıcı ile ezilir. Ayrı bir tencerede un ve su karıştırılarak orta ateşte pişirilir daha sonra Karşi küçük servis kaplarına konarak ortaları açılır ve içine keten tohumu yağı yaklaşık bir çay kaşı kadar konularak servis edilir. Keten tohumuna Güneyköy’de "Çiko" denilmektedir.

Güneyköy mutfağında Dağıstan'a özgü geçmişten günümüze gelen diğer bir tatlı ise Karşi (Dağıstan Muhallebisi) dir. Karşi muhallebisi; özellikle Yalova Güneyköy kültüründe loğusa olan kadınlara çabuk toparlanmaları, sütlerinin olması ve belirli nedenlerden ameliyat olmuş kişilere iç yaralarının iyileşmesi için yedirilen bir neyi ilaç olarak tüketilmesi yanında hoş şekerli tadı ile de Güneyköy’de gelen misafirlere de ikram edilmektedir.

\section{Hinkali Dağıstan Mantısı}

\section{Malzemeleri}

İç Harç Malzemeleri

- 1 kg orta yağlı dana kıyması

- 1 kg kuru soğan

- $250 \mathrm{ml}$ üzüm sirkesi

- 15 gr sarımsak

- Sivi yağ

- Tuz

- Karabiber

\section{Hamur Malzemeleri}

- $1.5 \mathrm{~kg}$ un

- 30 gr tuz

- $50 \mathrm{ml}$ üzüm sirkesi

\section{Sos Malzemeleri}

- Kirmızi toz biber

- Tereyağ1

- Kuru nane

- Sarımsak

- İsteğe göre yoğurt

- Sirke 
Yapılışı: Tencere içine yemeklik doğranmış kuru soğan ve sıvı yağ konur. Kıyma ve diğer malzemeler eklenerek iç harç kavrulur. Soğumaya bırakılır. Hamur malzemeleri karıştırılır ve sert bir hamur yapılarak dinlendirilir. Hamur, bezelere ayrılır ve bezeler merdane ile açılarak yuvarlak kalıpla daire şekli çıkarılır ve hamur içine iç harç konur. İç harç konan hamur aşağıdan yukarıya doğru iki uç kısmı birbirlerine alt üst gelecek şekilde örülür. Her bir örülen mantı yüzeyinde 18-20 arasında örgü izi oluşmalıdır. Hazır hale gelen hinkal suda haşlanır ve sudan süzülen hinkal tabaklara servis edilir üzerine ayrı yerde tereyağını eriterek üzerine toz biber ve nane kavrulur. İsteğe bağlı şekilde sarımsaklı yoğurt ve yağlı sosla tüketilir. Fakat Güneyköyde yöre halkı Dağıstan mantısı Hinkal'i yoğurt olmadan tüketirler. Üzüm sirkesi içine ezilmiş bol sarımsak, mantılar ister batırılarak ister Hinkal üzerine kaşık yardımıyla dökülerek yenmekte.

Dağıstan'a özgü Güneyköy 'de yapılan hamur işleri arasında yer alan bir mantı türü Hinkali'dir. Hinkal; tek lokmada yenen hamur olarak tanımlanmaktadır. Dağıstan mantısı; Hangel, Khinkali, Hıngel, Xıngal, Hıngel/Hengel gibi teleffuzlara sahiptir. Hamur ile yapılan ve arasına et, patates, peynir konularak yapılan bir yemek olan etli mantı türüdür. Bu yemek, tereyağı sosu ile yenmektedir (Kemaloğlu, 2012).

\section{Muçari (Tuzlu Kek)}

\section{Malzemeleri}

- 1 küçük adet sakız kabak

- 1 küçük adet kuru soğan

- 20 gr iç yağ

- 100 gr sucuk

- 3 adet yumurta

- $40 \mathrm{ml}$ ayçiçek yağ1

- Kuru nane

- 280 gr un

- Kirmizi pul biber

- Tuz

- 15 gr. kabartma tozu

Yapılışı: Tüm malzemeler bir kap içinde karıştırılır ve yağlanmış kek kalıbına, hazırlanan harç dökülür ve $180^{\circ} \mathrm{C}$ ısıdaki fırında pişirilir. 
Muçari, Güneyköy mutfağında yer alan Dağıstan'a özgü hamur işleri arasında yer alan ikindi çayı ile tüketilen misır unu ve kabak ile yapılan pratik tuzlu bir kektir.

\section{Natuh}

\section{Malzemeleri}

- Beyaz susam 480 gr

- Toz şeker $180 \mathrm{gr}$

- $\mathrm{Su}$; şekeri islatacak kadar

- Limon tuzu $1 \mathrm{~kg}$

Yapılışı: Bir orta boy tencereye toz şeker konur, üzerine 1slatacak kadar su ilave edilir ve ikisi birlikte kaynatılır. Ayrı yerde bir çay tabağına su konur ve bu kaynatılan karışımdan tabağın içine bir damla akıtılır, dağılmadan sert bir şekilde suyun içine düşerse şeker su karışımı istenilen kıvamda olmuş demektir. Daha sonra limon tuzu karışıma ilave edilerek, soğumadan kavrulmuş susamın üzerine dökülür ve çok hızlı bir şekilde karıştırılır.

Yalova Güneyköy'de yapılan Dağıstan'a özgü Kafkas tatlılarından birisi Natuh'dur. Dağıstan'dan Yalova Güneyköy’e yerleşen halk geçmişten günümüze kadar kültürel lezzetlerini de korumuşlardır ve bugüne kadar Natuh tatlısı köy sakinleri tarafından özel günler dışında da yapılıp tüketilmektedir. Hafif nemlendirilmiş bir tepsi üzerine dökülür, yüzeyi düzeltilir ve tatlı yüzeyinin pürüzsüz olması sağlanır. Ilık iken küçük küpler halinde kesilerek şekil verilir. Tatlı, soğuduktan sonra cam kavanozlarda rutubetsiz bir yerde saklanır.

Natuh tatlısı için, susam yerine ceviz, fındık, fıstık, kabak çekirdeği içi, ay çekirdeği içi ve benzeri kuruyemiş ürünler kullanılabilir. Kuruyemişlerin hemen hemen hepsinin tatliya katılmadan önce içindeki nemin yok edilmesi amacıyla kavrulur ve dış zarlarının çıkarılması gerekir. Bu şekilde hazırlandığında kavrulan kuruyemiş içinde kendi aromasını hapsetmiş olacak ve daha lezzetli bir tatlı haline gelmiş olacaktır.

\section{Zuraced Pidesi}

\section{Malzemeleri}

- Un 500 gr

- Yeterince $11 \mathrm{k}$ su ve tuz.

\section{İç Harç Malzemeleri}

- 500 gr kiyma 
- Kuru soğan orta boy 5 adet

- Domates $200 \mathrm{gr}$

- Tuz 10 gr

- Karabiber 6 gr

- Üzüm sirkesi $10 \mathrm{ml}$

- Pideyi pişirmek için yeterince tereyağı.

Yapılışı: Hamur yoğurma kabına alınan tuz ve un karıştırılır, üzerine yeterince su ilavesi ile sert bir hamur yoğrulur. Hamurun dinlenmesi için üstü kapalı olarak bekletilir. Dinlenen hamurdan 15 gr kadar parçalar kesilir. Her birini yaklaşık $20 \mathrm{~cm}$ büyüklüğünde, kalınca açılır. İç malzemesi için kıymayı, rendelenmiş soğanı, sirkeyi, domatesi, tuzu ve karabiberi karıştırılır. Hazırlanılan iç harçtan yufkanın yarısına kadar konarak harç el yardımıyla yayılır. Diğer boşta kalan kenarını üzerine kapatarak sıkıca kapatılır. Saçta ve veya yapışmaz tavada arkalı önlü pişirilir.

\section{SONUÇ}

Günümüzde önceden işletmeler arasında yaşanan rekabet şehirler hatta yöreler arasına taşınmıştır. Rakipler arasından sıyrılmak ve ön plana çıkmak isteyen yörelerin kendilerine özgü tüm özellikleri ve çekicilik unsurlarını doğru kullanmaları gerekmektedir. Yöreye özgü çekicilik unsurları arasında yöresel mutfaklar ön plana çıkmaktadır.

Turizmin farklı alanlarda kendini göstermesi gastronomi turizmini doğurmuş ve yöreler sahip oldukları yöresel mutfak özellikleri ile cazibe merkezleri haline gelmeye başlamışlardır. Bu kapsamda önemli bir çekicilik unsuru olarak yöresel mutfaklar; turistler açısından önemli bir cazibe unsuru olmanın yanında, yöreyi ziyaret edenlerin yeme-içme ihtiyacını karşılaması nedeniyle de turizmi destekleyici bir yapı olarak ortaya çıkmaktadır. Turizm olgusunun gelişmesiyle birlikte gastronomi turizmi kapsamında yöresel mutfaklar ele alınmakta hem kültürün yaşaması ve aktarımında hem de yörenin ve yemeklerinin tanıtımında etkin rol oynayarak yöreye başta ekonomik açıdan olmak üzere farklı katkılar sağlamaktadır.

Tarihsel süreçte yaşanılan savaşlar, yaşam koşulları gibi pek çok unsur insanların beslenme kültürlerini de etkilemiştir. Kafkasya'dan göç etmek zorunda kalan bir topluluk olan Dağıstanlılar da yerleştikleri yerlerde kültürlerini devam ettirme başarısını göstermiştir. Bulundukları bölgede kendi kültürlerini korumanın yanı sıra, içinde bulundukları çevrenin de mutfak kültürünü şekillendirmişlerdir. Türkiye coğrafyasında farklı yemek kültürlerinin birleşimi ile oluşan zengin bir mutfak kültürü bulunmaktadır. Dağıstanlıların mutfak kültürü de bunlardan biridir. Bu çalışmada Dağıstanlıların mutfak kültürünün incelenmesi ve kayıt altına alınması araştırmanın amacını oluşturmaktadır. 
Çalışmada Yalova’ya göç eden Dağıstanlıların yaşadığı bir köy olan Güneyköy mutfak özellikleri açısından incelenmiştir. Nitel araştırma tasarımına uygun olarak yürütülen çalışmada, Güneyköy’de Dağıstanlılar geçmişten günümüze gelen mutfak kültürlerini koruyarak, geleneksel özelliklerini sürdürmektedirler. Güneyköy mutfağının öne çıkan özellikleri yemeklerde üzüm sirkesi ve sarımsak kullanmanın yanında teknik olarak haşlama yöntemini kullanmaktadırlar. Dağıstan mutfağında yağda kızartma tercih edilmemektedir.

Yemek yeme, sadece seyahat deneyiminin sonucu değildir. Aynı zamanda tatile çıkan insanların dışarıda yemek yeme faaliyeti, bir öğünün zevk elde etme ve deneyim yaşama amacı ile gerçekleştirildiği bir faaliyettir. Turistler yerel mutfakla ilgileniyorlarsa, bu katılım onların yerel mutfağa ilişkin algılarını ne yönde etkileyebilir (Guan ve Jones, 2015).

Güneyköy, Dağıstanlıların yoğun olarak yaşadığı bir yöredir. Burada, Dağıstan mutfak kültürünün devam ettirilmesi özellikle yöresel ürünlere ilgi duyan turistlerin ilgisini çekebilecek bir destinasyondur. Bu çalışmada, Dağıstan mutfak kültürüne ait elde edilen bilgiler sunulmuştur. Yöresel lezzetlerin satışının yapıldığı küçük bir işletme dışında, turizm işletmesi bulunmamaktadır. Bu açıdan yörenin sahip olduğu mutfak kültürünün daha aktif bir biçimde geliştirilmesi önerilmektedir. LopezGuzman ve Sanchez-Canizares (2012) tarafından yapılan ve İspanya'nın Cordoba kentini ziyaret eden turistlerin seyahat nedenlerini inceleyen bir çalışmada, yerel mutfağın ziyaret için birinci veya ikinci en önemli seyahat motivasyonu olduğu saptanmıştır. Su ve Horng (2012) ise kültürü aş1lamak ve yerel mutfağı deneyimlemenin önündeki engelleri azaltma yönündeki çabaların birçok destinasyonda pazarlama stratejisinin tasarlanmasında en önemli unsur olduğunu iddia etmişlerdir. Güneyköy’ün tanıtılması ve turizm değerlerini ürüne dönüştürülmesi sağlanabilir. Ardından, Dağıstan mutfağını deneyimlemek isteyen turistlere yönelik pazarlama stratejileri geliştirilebilir. İlk aşamada, yörenin günübirlik yerli turistlere yönelik tur rotalarına dahil edilmesi sağlanabilir. Özellikle Yalova’ya termal turizm için gelen turistlerin Güneyköy’e uğramaları ile yörenin tanıtımı yapılabilir. Burada hizmet sunan işletmede satışa sunulan ürünler de (bakuk, natuh, sirke vb.) bulunmaktadır. Güneyköy’e gelen turistlerin Mehmet Reşad Han Çeşmesi, Eski Cami, Güneyköy’ün tarihi evlerini ziyaret edebileceklerdir. Tarihi evlerin Yalova Valiliği tarafından özel bir proje ile yenilenmesi hedeflenmektedir. Bu proje tamamlandığında tarihi evlerin (Resim 3) ziyarete açılması ile bu değerlerde ekonomiye gelir sağlayabilecektir. Güneyköy, Yalova 'nın turizmde adından söz ettirebilmesi için sahip olduğu önemli bir kaynaktır. Bundan sonra yapılacak çalışmalarda da bu değerin daha fazla geliştirilebilmesi için öncelikle yöre halkının turizme yönelik beklentileri araştırılmalıdır. Ardından, yörenin sürdürülebilir turizm anlayışı içinde bozulmadan korunarak, turizm faaliyetlerinin planlanması sağlanmalıdır. 
Bu araştırma Yalova Güneyköy'de yaşatılan Dağıstan kültürünün bir parçası olan Dağıstan mutfağı ile sınırlıdır. Dağıstan mutfağının tanıtılması için Güneyköy bir çekicilik unsuru olarak değerlendirilebilir. Konu ile ilgili sivil toplum kuruluşları ve yerel yönetimler birlikte hareket ederek, Yalova’yı tanıtan etkinlikler içerisinde Güneyköy’e ayrı bir yer verilerek geçmişten günümüze gelmiş olan Dağıstan yemekleri tanıtılmalıdır. Ayrıca medyanın da yöreye ilgi göstermesi sağlanarak gerek görsel medyada gerekse sosyal medyada Güneyköy ve Dağıstan yemeklerine daha fazla yer verilmelidir. Araştırma sürecinde karşılaşılan güçlüklerin başında Güneyköy ve Dağıstan yemekleri hakkında yazılı materyallere ulaşılamamasının yanında internet ortamında da çok sınırlı bilgiye rastlanılmıştır. Araştırmanın bu yönüyle ilgili literatüre katkı sağlaması beklenilmektedir. 


\section{KAYNAKÇA}

Avcıkurt, C. (2005). Turizmde Tanıtma ve Satış Geliştirme, Değişim, İstanbul.

Bessiere, J. (1998). "Local Development and Heritage: Traditional Food and Cuisine as Tourist Attractions in Rural Areas”, European Society for Rural Sociology, 38 (1), 21-34.

Boydak, M. (2011). "Araştırma ve Yayın Etiği”. Bilim Etiği (Ed. Atasoy, N, Boydak, M., Çırpan, H. A., Kendigelen, A., Meriç, İ. E., Sarıkayan, A. T., Ulubelen, A., Yazıcı, H. ve Yıldırım, N.), İstanbul Üniversitesi Yayın No: 5048, İstanbul.

Büyüköztürk, Ş., Kılıç Çakmak, E., Akgün, Ö. E., Karadeniz, Ş. ve Demirel, F. (2019). Eğitimde Bilimsel Araştırma Yöntemleri, Pegem, Ankara.

Charzyński, Przemysław, Podgórski, Zbigniew, Dąbkowska, Anna ve Stawska, Monika. (2017). "Assessment of the Recognisability and Attractiveness of Regional Kinds of Polish Cuisine in the Context of Culinary Tourism", Geography and Tourism, 5 (1), 7-18.

Cohen, E., ve Avieli, N. (2004). "Food in Tourism: Attraction and Impediment", Annals of Tourism Research, 31 (4), 755-778.

Çalışkan, O. (2013). "Destinasyon Rekabetçiliği ve Seyahat Motivasyon Bakımından Gastronomik Kimlik", Journal of Tourism and Gastronomy Studies, 1(2), 3-12.

Duman, T. ve Öztürk, A. B. (2005). "Yerli Turistlerin Mersin Kızkalesi Destinasyonu ve Tekrar Ziyaret Niyetleri ile İlgili Algılamaları Üzerine Bir Araştırma”, Anatolia: Turizm Araştırmaları Dergisi, 16(1), 9-23.

Eldarov, Eldar M., Gadzhiev, Magamedkamil D. ve Vagabov, Makhach M. (2017). "Methods of Study and Practical Analysis of Culinary Tourism in Dagestan", International Journal of Sciences and Research, 73 (4), 65- 76.

Guan, Jingjing Jones, David L. (2015) "The Contribution of Local Cuisine to Destination Attractiveness: An Analysis Involving Chinese Tourists' Heterogeneous Preferences", Asia Pacific Journal of Tourism Research, 20 (4), 416-434.

Hacıoğlu, N., Girgin, G. K. ve Giritlioğlu, İ. (2009). "Yiyecek-İçecek İşletmelerinin Pazarlama Faaliyetlerinde Yöresel Mutfakların Kullanımı-Balıkesir Örneği”, III. Gastronomi Sempozyumu, 17-18 Nisan 2009, Antalya.

Haven-Tang, C. and Jones, E. (2006). "Using Local Food and Drink to Differentiate Tourism Destinations through a Sense of Place: a Story From Wales-Dining at Monmouthshire's Great Table", Journal of Culinary Science \& Technology, 4(4), 69-86.

https://www.kulturportali.gov.tr/turkiye/yalova/kulturenvanteri/mehmet-resat-hancesmesi (15.11.2019). 
http://yalovakentmuzesi.gov.tr/tarihi-eserler/yalova-merkez-ilce-guneykoyde-bina/ (08.11.2019).

http://www.kulturportali.gov.tr/turkiye/yalova/nealinir/boynuz-ve-gumus-sleme-takilar $(15.11 .2019)$

Jalis, M. H., Che, D. ve Markwell, K. (2014). "Utilising Local Cuisine to Market Malaysia as a Tourist Destination", Procedia- Social and Behavioral Sciences, 144, 102110 .

Karaca, E ve Sarışık, M. (2018). "Yöresel Mutfakların Kendi Destinasyonları Dışındaki Faaliyetlerinde Karşılaşılan Sorunlar Üzerine Bir Araştırma”, International Journal of Contemporary Tourism Research, 2 (2), 1-10.

Kemaloğlu, M. (2012). "Terekeme-Karapapah Türkleri Ağzına Ait Sözcükler MuşBulanık Çevresi”, Türkiyat Mecmuası, 22, 62-97.

Keskin, S. (2015). "Kocaeli Vilayetine Yerleştirilen Dağıstanlı Muhacirlerin Sultan Reşad Himayesinde Kurulan Reşadiye’ye (Güneyköy) İskanı ile Gerçekleşen İnşa Süreci”, Uluslararası Gazi Süleyman Paşa ve Kocaeli Tarihi Sempozyumu Bildiriler Kitab1, 2341-2373.

Kılıç, A. (2020). Tarihi Eserleri, Doğal Güzellikleri ve Kültürüyle Yalova, Yalova İl Özel İdaresi Kültür Yayınları 02, İzmir.

Kivela, J. J. ve Crotts, J.C. (2009). “Understanding Travelers' Experiences of Gastronomy through Etymology and Narration",.Journal of Hospitality and Tourism Research, 33 (2), 161-192.

Kozak, M. (2015). Bilimsel Araştırma: Tasarım, Yazım ve Yayım Teknikleri. Detay Yayınc1lı, Ankara.

Kozak, N., Kozak, M. A. ve Kozak, M. (2008). Genel Turizm: İlkeler ve Kavramlar, Detay Yayıncilık, Ankara.

Long, L. M. (2004). Culinary Tourism, The University Press of Kentucky, USA.

Lopez-Guzman, T. ve Sanchez-Canizares, S. (2012). "Culinary Tourism in Cordoba, Spain”, British Food Journal, 114 (2), 169-179.

Maviş, F. (2003). Endüstriyel Yiyecek Üretimi, Detay Yayıncılık, Ankara.

McKrecher, B. Okumus, F. and Okumus, B. (2008). "Food Tourism as a Viable Market Segment: it's all how You Cook the Numbers", Journal of Travel and Tourism Marketing, 2 (2), 137-148.

Mil, B. ve Denk, E. (2015). "Erzurum Mutfağ1 Yöresel Ürünlerin Otel Restoran Menülerinde Kullanım Düzeyi: Palandöken Örneği”, Uluslararası Sosyal ve Ekonomik Bilimler Dergisi, 5 (2), 1-7. 
Okumus, F., Kock, G., Scantlebury, M. M. G. ve Okumus, B. (2013). "Using Local Cuisines when Promoting Small Caribbean Island Destinations", Journal of Travel and Tourism Marketing, 30 (4), 410-429.

Öney, H. (2013). “Gastronomi Turizmi”, Alternatif Turizm (Ed. Bahçe, A. S.), Anadolu Üniversitesi Yayınları, Eskişehir.

Özbay, G. ve Çekin, A. (2020). "Turizm, Ulaşım ve Sosyal Medya Etkileşimi: Doğu Ekspresi ve Kars’taki Konaklama İşletmelerine Yönelik Bir Araştırma”, Ahi Evran Üniversitesi Sosyal Bilimler Enstitüsü Dergisi, 6 (1), 327-344.

Quan, S. \& Wang, N. (2004). “Towards a Structural Model of the Tourist Experience: An Illustration from Food Experiences in Tourism”, Tourism Management, 25, 297305.

Selwood, J. (2003). "The lure of Food: Food as an Attraction in Destination Marketing in Manitoba, Canada", Food Tourism around the World: Management of Development and Markets, (Ed. Hall, M.), Elseiver, Great Britain.

Su, C. S. ve Horng, J. S. (2012). "Recent Development in Research and Future Directions of Culinary Tourism: A Review", Visions for Global Tourism Industry: Creating and Sustaining Competitive Strategies, (Ed.Kasimoglu, M.), InTech, Crotia.

Şengül, S. ve Genç, V. (2016). “Festival Turizmi Kapsamında Yöresel Mutfak Kültürünün Destekleyici Ürün Olarak Kullanılması: Mudurnu İpekyol Kültür Sanat ve Turizm Festivali Örneği”, Pamukkale Üniversitesi Sosyal Bilimler Enstitüsü Dergisi, 23, 79-89.

Şengül, S. ve Türkay, O. (2014). "Yöresel Mutfaklar Eğitimi Üzerinden Kimlik, Mutfak Kültürü ve Turizm Gelişimine Dair Çıkarımlar: Mudurnu Örneği”, Citta Slow EkoGastronomi Kongresi, Gökçeada.

Şengül, S. ve Türkay, O. (2018). "Yöresel Mutfak Motivasyon Unsurlarının Destinasyonu Tekrar Tercih Etme ve Başkalarına Önerme Üzerine Etkisi”, Yönetim ve Ekonomi Araştırmaları Dergisi, 16(4), 149-172.

Şengül, S. ve Türkay, O. (2015). "Gastronomi Turizmi Bağlamında Akdeniz Mutfak Kültürünün Turistik Ürün Olarak Kullanılması", IV. Doğu Akdeniz Turizm Sempozyumu, Hatay.

Şutanrıkulu, G. (2015). "Derbent Bölgesi Terekeme Türklerinin Aile Yaşantısındaki Sosyo-Kültürel Değişimler”, Batman Üniversitesi Yaşam Bilimleri Dergisi, 5(1), 139-150.

Ünyay Açıkgöz, F. (2019). “İspanya'dan Osmanlı’ya: Bazı Yeni Kaynaklar Işı̆̆ında Çikolatanın Tarihi Serüvenine Katkı”, Ahi Evran Üniversitesi Sosyal Bilimler Enstitüsü Dergisi, 5(1), 16- 27.

Orman ve Su İşleri Bakanlığı. (2012). Yalova Doğa Turizmi Master Planı, Yalova: Doğa Koruma ve Milli Parklar Genel Müdürlüğü Yalova Şube Müdürlüğü. 
Yıldırım, A. ve Şimşek, H. (2006). Sosyal Bilimlerde Nitel Araştırma Yöntemleri, Seçkin Yayıncılık, Ankara.

Zengin, K. (1987). Yalova, Edebiyat Fakültesi Basımevi, İstanbul. 
Resim 1. Sultan Reşat Çeşmesi

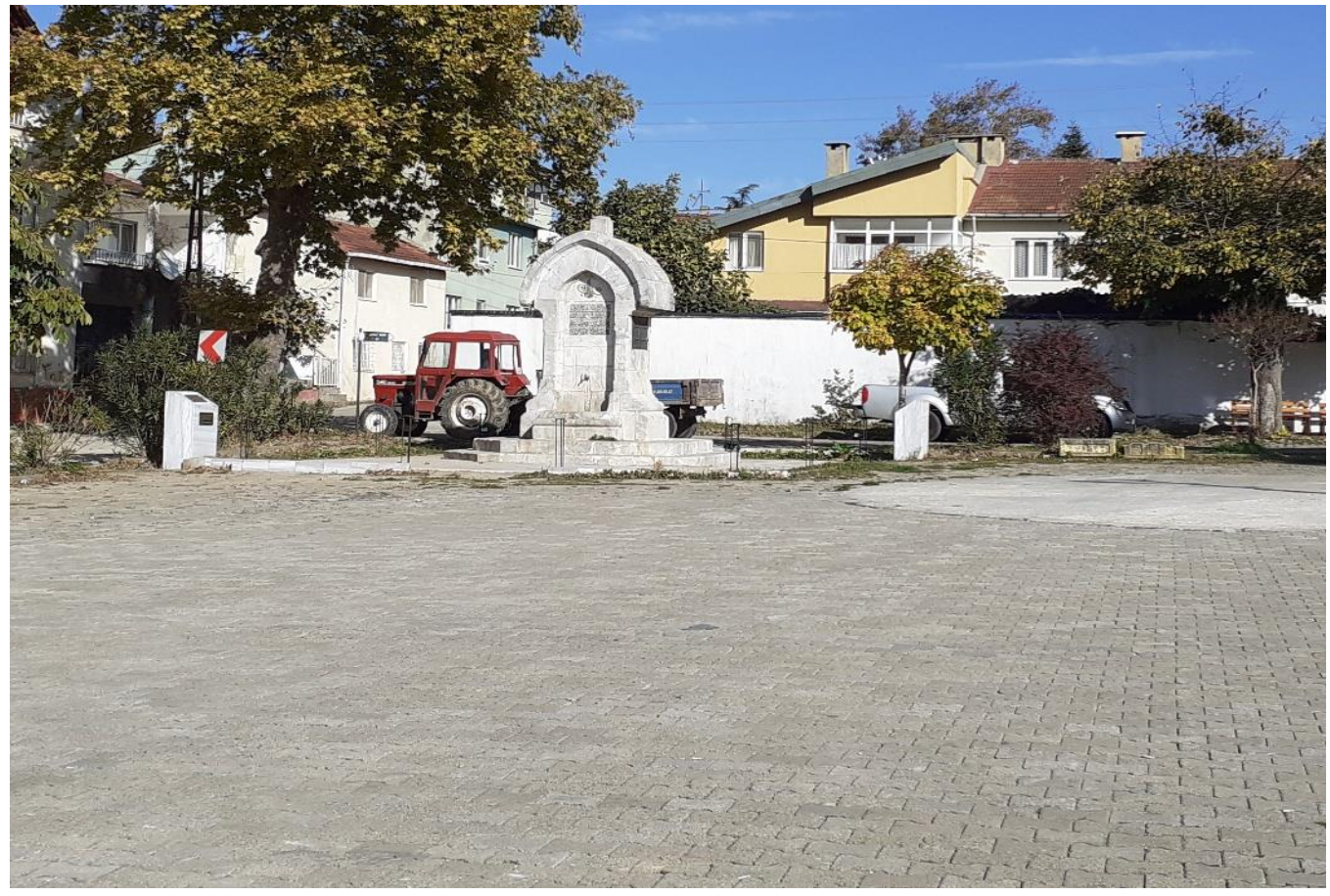

Kaynak: Yazarlar tarafından çekilmiştir.

Resim 2. Güneyköy'de Tarihi Ev

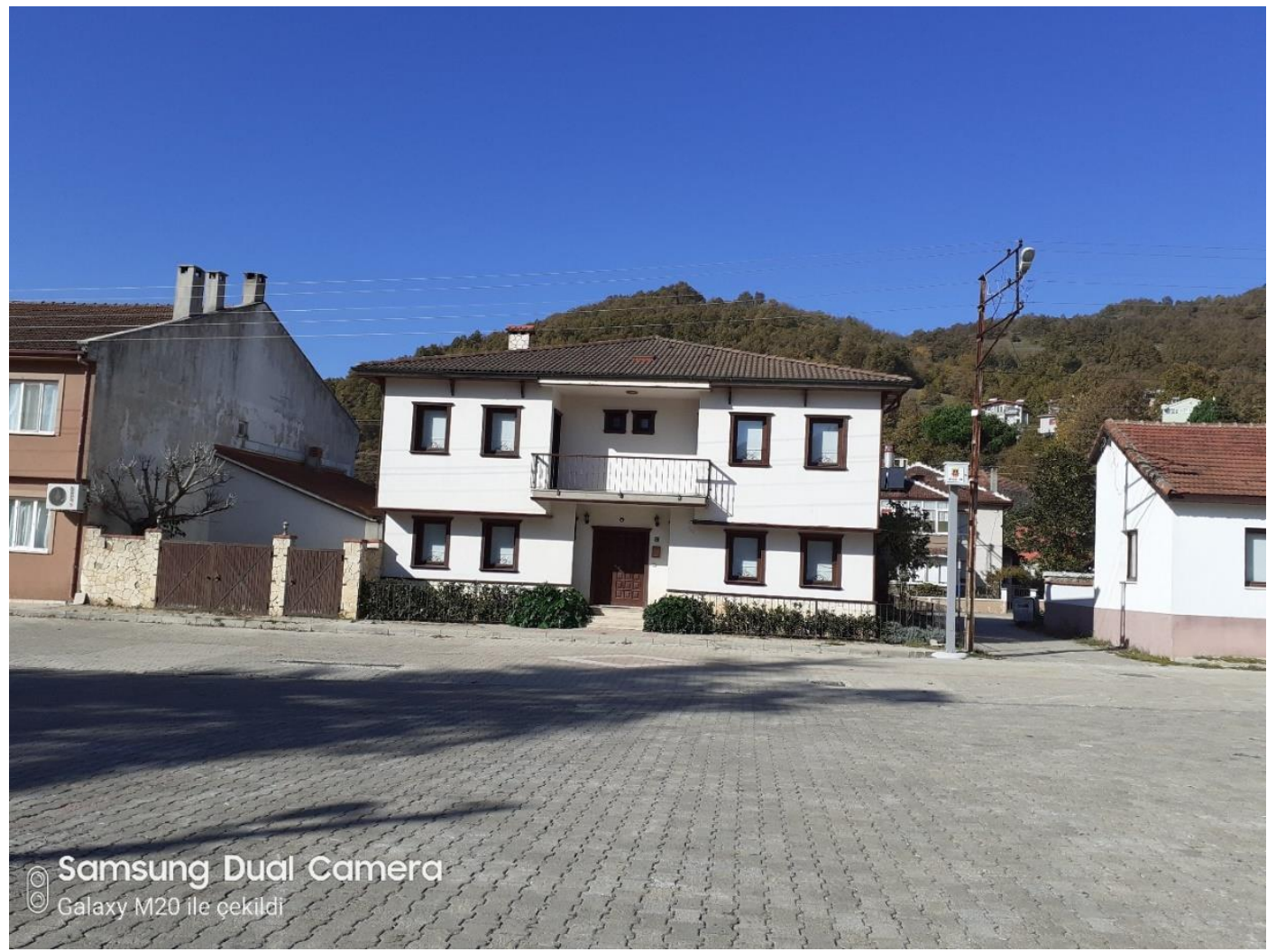

Kaynak: Yazarlar tarafından çekilmiştir. 
Resim 3. Gümüş ve Boynuz Takı Örnekleri

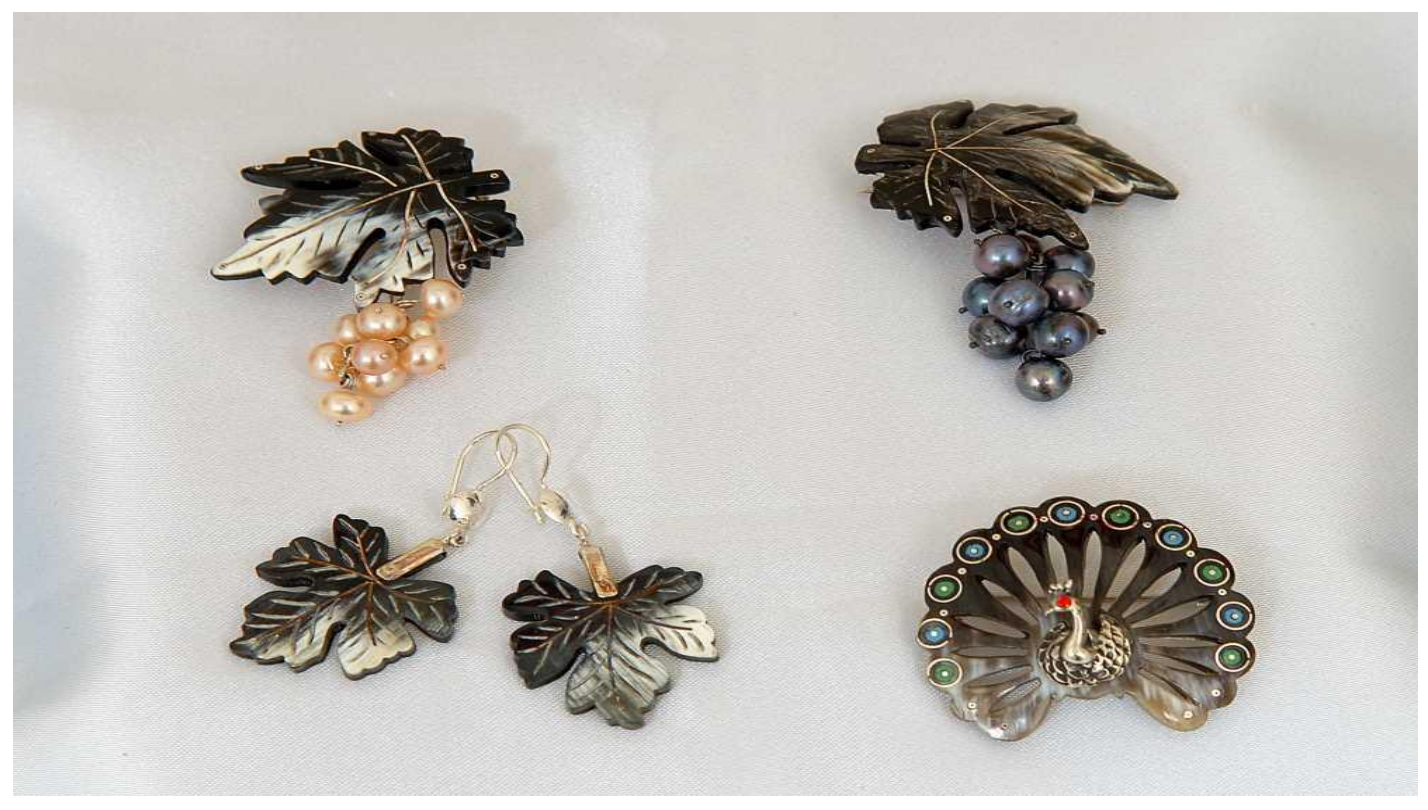

Kaynak: https://www.kulturportali.gov.tr/turkiye/yalova/nealinir/boynuz-ve-gumus-sleme-takilar 